\title{
S\&P 500 Index Direction Forecasting from 1976 to 2010: A Fuzzy System Approach
}

\author{
Cesar Duarte Souto-Maior Federal University of Santa Catarina. Brazil. cesarcdm@yahoo.com.br \\ José Alonso Borba. Federal University of Santa Catarina. Brazil. jalonso@ cse.ufsc.br
}

Newton C. A. da Costa Jr. Federal University of Santa Catarina. Brazil. newton@ cse.ufsc.br

\begin{abstract}
Investors are not always completely rational and they do not always work only with numbers. Sometimes, they use linguistic concepts to make their decisions. Fuzzy logic is helpful in handling such situations. This article differs from other studies in this area by applying fuzzy logic for forecasting the direction/sign of stock market indexes. The article also presents a model for forecasting the direction/sign of stock market indexes using a fuzzy system, and this model is applied in the prediction of the S\&P 500 Index. The rules of the model were established between 1970 and 2009, and the test period was from 1976 to 2010. Despite the fact that the estimated model produced a linguistic output, it was possible to delineate a statistically significant investment strategy, which outperformed a buy-and-hold one. In addition, the success rate calculated was also statistically significant. Another difference from other studies is that the proposed model does not return an exact output, but a probabilistic one of linguistic variables. The proposed model, with its probabilistic output, can be used as a support for investment decisions. In other words, the linguistic output does not force the investor to blindly follow the proposed strategy.
\end{abstract}

Keywords: Fuzzy logic; Stock market index; Forecasting; S\&P 500.

\section{INTRODUCTION}

The rise of efficient market hypotheses brings popularity to stock market indexes trading. Beating the market is difficult, so a stock index investment seems to be a good alternative. For Chen, Leoung, \& Daouk (2003), an index provides an effective way of reducing risk. According to Armano, Marchesi, \& Murru (2005), this reduction occurs because the impact of bad news from a unique corporation is minimized. In addition, stock indexes provide a reference to investors about the profitability of a particular market.

Since the 1980s, the literature related to financial time series has produced important studies that have questioned the (weak) efficient market and the 
random-walk hypotheses (e.g., see Lo \& Mackinlay, 1988; Poterba \& Summers, 1988; Fama \& French, 1988). These authors claim that considerable evidence exists that stock returns are, to some extent, predictable. They show strong evidence of conditional heteroskedasticity in many financial time series, meaning that these time series returns are not independent and are identically distributed as established by the random-walk model. According to Yeh, Huang, \& Lee (2011), the stock time series are inherently noisy and non-stationary. Chun, Kim, \& Kim (2002) argue that financial markets can be predictable, but they exhibit nonlinear dynamics with a chaotic behavior.

These facts have provoked theoretical and practical interest in the nonlinear financial time series models based on techniques such as auto-regressive movingaverage (ARMA) family, generalized auto-regressive conditional heteroskedasticity $(\mathrm{GARCH})$ family, and, more recently, methods based on artificial intelligence such as artificial neural networks (ANN), genetic algorithms (GA), and fuzzy logic (FL).

Predictability of financial time series can be viewed in two different ways: forecasting by level (value) estimation models and forecasting by classification models. The first method relies on accurate prediction of the price level of stocks, indices, and other financial series instruments. (e.g., see Teixeira \& Rodrigues, 1997; Chakraborty, 2006; Dutta et al., 2006; Panda \& Narasimhan, 2006; Sohn \& Lim, 2007; Majhi et al., 2009; Mostafa, 2009; Chen, Hsin \& Wu, 2010, Shen et al., 2011). The degree of accuracy and the acceptability of the forecast are measured by its deviation from the actual observations, thus minimizing forecasting errors. The second method is guided by forecasts on the direction/sign of the changes in price levels. This latter approach is defended by some authors (e.g., see Wu \& Zhang, 1997; Aggarwal \& Demaskey, 1997; Tsaih, Hsu \& Lai, 1998; Leung, Daouk \& Chen, 2000; Chen, Leung \& Daouk, 2003; Kim, Min \& Han, 2006; Faria et al., 2009; Lu, 2010; Na \& Sohn, 2011), who claim that trading driven by a certain forecast with a small forecast error may not be as profitable as trading based on an accurate prediction of the direction/sign of the movement.

At the same time, several researches in the area of business have used fuzzy logic to handle imprecise information and improved results. Some of them are Shehab \& Abdalla (2002) and Murcia, Borba, \& Souto-Maior (2005) in a costing system; Sahin \& Dogan (2003) in supplies and customers relationship; Jiang \& Hsu (2003) in manufacturing and business cycle evaluations; Lin, Hwang, \& 
Becker (2003) in accounting frauds detection; Beynon, Peel, \& Tang (2004) in price composition of auditing services; Wang \& Hsu (2008) in tourism demand; Keles, Kolcak, \& Keles (2008) in domestic debt; Wang, Chang, \& Tzeng (2011) and $\mathrm{Wu}(2010,2011)$ in automobile sales; and Cheng, Tsai, \& Sudjono (2010) in project cash flow control.

In the area of finance, works related to stock selection (such as Tanaka \& Guo, 1999; Inuiguchi \& Tanino, 2000; León, Liern \& Vercher, 2002; Wang \& Zhu, 2002; Serguieva \& Hunter, 2004; Tiryaki \& Ahlatcioglu, 2009), option pricing (Thavaneswaran, Appadoo \& Paseka, 2009), and insolvency prediction (Tseng \& Lin, 2005; Vigier \& Terceño, 2008; Chen, Huang \& Lin, 2009) have also used fuzzy logic.

Works that use fuzzy logic to select and forecast specific stocks do not take advantage of the benefits from stock market index trading. According to the CAPM model, great performance could be generated by choosing stocks with high beta values and with bigger risks as well. Some of them are Simutis (2000) with an expert system; Dourra \& Siv (2002) with technical indicators; and Atsalakis \& Valavanis (2009) and Hadavandi, Shavandi, \& Ghandari (2010) with neural networks.

In stock index prediction, some works deal with level forecasting using fuzzy logic (Huarng, 2001a, 2001b; Yu, 2005a, 2005b; Huarng \& Yu, 2005, 2006; Chen, Cheng \& Teoh, 2007, 2008; Chu et al., 2009) and hybrid models with rough sets (Teoh et al., 2008, 2009), Markov chain concept (Wang, Cheng \& Hsu, 2010), or neural networks (Cheng, Wei \& Chen, 2009; Yu \& Huarng, 2008, 2010; Boyacioglu \& Avci, 2010), but none of them deals with forecasts on the direction/sign of the changes in price levels. In addition, according to Leung, Daouk, \& Chen (2000), forecasting strategies based on levels seem to be less profitable than forecasting strategies based on the change of direction/sign of a stock index.

This article differs from other studies in this area by applying fuzzy logic for forecasting the direction of the change in stock market indices level. Another difference is that the proposed model does not return an exact output, but a probabilistic one of linguistic variables. This linguistic output can be used with other economic and non-economic information, including intuition, to help in making investment decisions. Based on the output model, an investment strategy could be created and compared with a passive one. 
The article is organized as follows. In Section 2, fuzzy logic and its concepts are briefly described. Section 3 presents the methodology used. Empirical results are presented in Section 4. Section 5 is a conclusion of the work.

\section{FUZZY LOGIC}

According to binary logic, which was initially formulated by the Greek philosopher Aristotle (384-322 A.C.), a proposition is either true or false. This type of logic assumes that the states of nature are well-defined events. However, in most contexts such as the accounting and business areas, the states of nature are vague, and transitions between 'what is' and 'what is not' are not very well defined.

Zadeh (1965) published the first paper about fuzzy logic called Fuzzy Sets. The model was developed to convert subjective values into objective ones. A fuzzy set does not have precise and limited boundaries; the difference between belonging and not belonging does not exist, only a degree of pertinence exists. According to Zebda (1998), the fuzzy sets theory is not a decision theory but rather a calculus (a modeling language) wherein vague humanistic events can be treated in a systematic manner.

The main objective of fuzzy logic is to provide concepts that perform approximate reasoning. Fuzzy logic assumes a degree of pertinence in the 0 to 1 range, which permits the fuzzy set element to be partially true or partially false.

Bojadziev \& Bojadziev (1997, p. 9) define a fuzzy set as

$$
\mathrm{A}^{\prime}=\{(x, \mu a(x)) \mid x \in \mathrm{A}, \mu a(x) \in[0,1]\},
$$

where $\mu a(x)$ is called function of pertinence and specifies the grade in which each element $x$ in A belongs to the fuzzy set $\mathrm{A}^{\prime}$.

According to von Altrock (1997), the theory of fuzzy sets is a generalization that covers the classical sets where $\mu a(x)=0$ or $\mu a(x)=1$. In other words, the classical sets are special cases of the fuzzy sets. Table 1 and Figure 1 show the differences between classical sets and fuzzy sets. 


\begin{tabular}{c|c}
\hline Classical sets - Binary logic & Fuzzy sets - Fuzzy logic \\
\hline Precise boundaries & Imprecise boundaries \\
\hline $\begin{array}{l}\text { Rough transition between belonging and } \\
\text { not belonging }\end{array}$ & $\begin{array}{c}\text { Smooth transition between belonging and } \\
\text { not belonging }\end{array}$ \\
\hline Represents well-defined concepts & Represents imprecise and vague concepts \\
\hline
\end{tabular}

Table 1. Classical sets versus fuzzy sets.

A

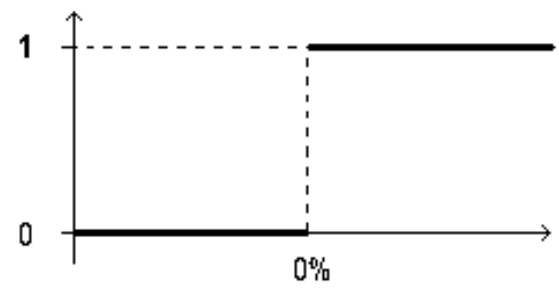

B

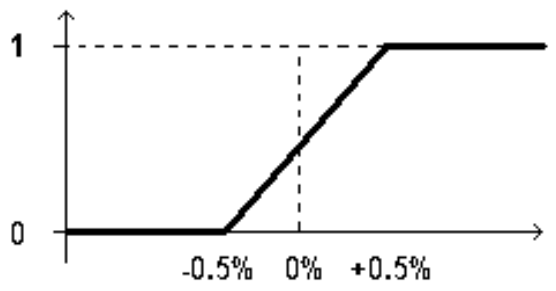

Figure 1. Classical sets versus fuzzy sets

Figure 1, part A, shows an example of classical logic. If the index variation is positive, the variation is considered "up" and if it is negative, the variation is considered "down". There is a rough transition between "up" and "down". Infinitesimal negative values are classified as "down", and infinitesimal positive values are classified as "up". However, the market could classify both values as the same information, and a system based on classical logic could not present a good performance. Figure 1, part B, shows how fuzzy logic can be used to delineate a smooth transition between "up" and "down" variations.

\section{METHODOLOGY}

\subsection{The model}

Figure 2 illustrates the proposed model. It is divided into three main parts: the fuzzification of input variables, inference rules, and output variables. Here, fuzzification (defuzzification) implies the conversion of a numeric (linguistic) value into a linguistic (numeric) one. 


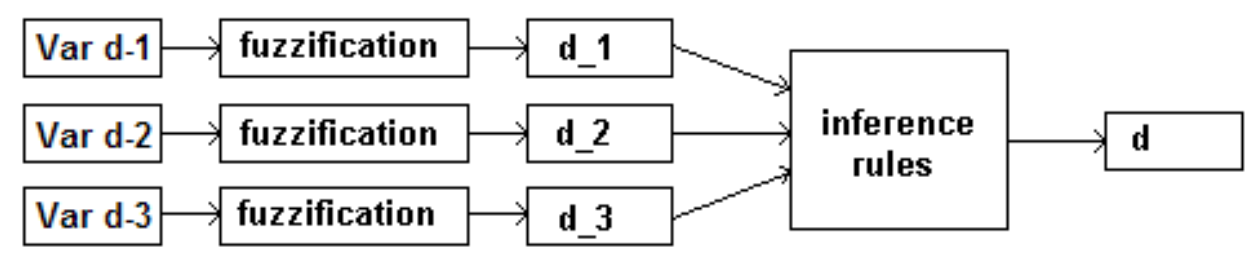

Note:

Var d-1, Var d-2, and Var d-3 are the percentage variations (in numeric values) of the index on days d, d-1, d-2, and $\mathrm{d}-3$, respectively. $\mathrm{d} \_1, \mathrm{~d} \_2$, and $\mathrm{d} \_3$ are the percentage variations (in linguistic values) of the index on days d, $\mathrm{d}-1, \mathrm{~d}-2$, and $\mathrm{d}-3$, respectively. $\mathrm{d}$ is the linguistic output of the model.

Figure 2. General view of a fuzzy model for stock market index forecasting

The conceptual model is divided into four main parts: (1) choice of variables for the forecasting model; (2) fuzzification; (3) inference rules; and (4) output variables. Each of these parts is described next.

\subsubsection{Choice of variables of the forecasting model}

In the work by Kamitsuji \& Shibata (2003), the percentage variations of the index on the three days before the day to be forecasted were chosen as input variables. Kamitsuji \& Shibata (2003) also tested their model for four and five daily variations, but these additional data produced worse results. These authors argue that these additional data cause an over-fitting in neural network training; in other words, the system becomes very specific and loses generalization to the subsequent periods.

Percentage variations of the index on the three days before the day to be forecasted were chosen as input variables. This choice is based on O'Connor, Remus and Griggs (1997). They show that individuals present different tendencies and behavior for up and down series. In this method, an investor could make decisions based on recent information. As an example, if a stock price increases during many consecutive days, it could provoke a selling behavior that would drive the stock price down, despite a positive macroeconomic scenario. On the other hand, if the stock price decreases during many consecutive days, it could provoke a buying behavior and a tendency to increase the stock price, despite a negative macroeconomic scenario.

In order to calculate the percentage variation on day $d$, the following formula was used: 


$$
\operatorname{Var}_{d}=\frac{\left(V_{d}-V_{d-1}\right)}{V_{d-1}},
$$

where $V a r_{d}$ is the percentage variation (in numeric values) of the daily variation or return of the index on day $\mathrm{d} ; V_{d}$ and $V_{d-1}$ are the closing index values on days $\mathrm{d}$ and $\mathrm{d}-1$, respectively.

The same logic will be applied to calculate the percentage variation of daily variation of the index on days $\mathrm{d}-1, \mathrm{~d}-2$, and $\mathrm{d}-3$.

\subsubsection{Fuzzyfication}

An investor does not always think mathematically with numbers. Sometimes an investor rationalizes with linguistic terms such as "up", "down", "expensive" or "cheap". To use fuzzy logic, all numerical input variables should be converted to linguistic variables. In this work, the input linguistic variables adopted were "up" and "down".

To accomplish this task, pertinence functions were developed. Figure 3 shows a pertinence function for the linguistic variable $d_{-} 1$, related to the numeric variation of day $\mathrm{d}-1$, the previous day.

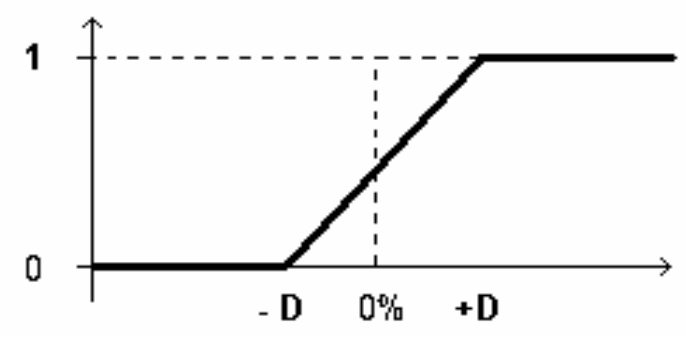

Figure 3. Graphic depiction of pertinence function "up" to d_1 linguistic variable

This pertinence function can be described in the following manner:

$$
\mu s=\left\{\begin{array}{llc}
0 & \text { if } & \boldsymbol{V a r} \boldsymbol{d}_{\boldsymbol{d}-1} \leq-\boldsymbol{D} \\
1 / 2+\boldsymbol{V a r _ { d - 1 } / 2 \boldsymbol { D }} & \text { if } & -\boldsymbol{D}<\boldsymbol{V a r _ { d - 1 }}<+\boldsymbol{D} \\
1 & \text { if } & \boldsymbol{V a r _ { d - 1 }} \geq+\boldsymbol{D}
\end{array}\right.
$$

where $\mu s$ is the pertinence function "up", and $V a r_{d-1}$ is the percentage variation (in numeric value) of day $\mathrm{d}-1$. 
In other words, beyond a certain value $+\mathrm{D}$, the index variation is "up", below $\mathrm{D}$ is not "up", and between $-\mathrm{D}$ and $+\mathrm{D}$ is "partially up". The pertinence function "down" is very similar.

The choice of $\mathrm{D}$ value is important. Beyond what would D value investors classify a percentage variation as "up"? Souto-Maior (2007) tests several values of D. Small and big values are not good choices. As a rule-of-thumb, D could be chosen as the fifth of daily percentage variation standard deviation. In the initial period from 1970 to 1974 (five years) the daily percentage variation standard deviation was around $1 \%$. Therefore, in this work, we use $0.2 \%$ as the $\mathrm{D}$ value. Finally, we test other D values to verify the effectiveness of this rule-of-thumb.

\subsubsection{Inference Rules}

After the fuzzification of all input values, the step that follows involves the establishment of inference rules. These rules represent the way humans make decisions, inferring from linguistic premises. These rules are logical statements, and each rule can be assigned a value from zero to one, called Degree of Support (DoS), which depends on the characteristics of the sample. When a rule is assigned a DoS value equal to zero (one), the rule is considered insignificant (significant). The DoS also allows for values between zero and one for partially significant rules. Given next is an example of the rules used in our model.

If (d_3= "up" and d_2 = "up" and d_1 = "up"),

Then $d=$ "down", with a DoS of 0.53 .

To create the rules used in the model, the period from 1970 to 1974 (five years) was used as the estimation period for forecasting year 1975 and so on. Therefore, the period from 1970 to 2009 was used as the estimation period, and the period from 1976 to 2010 (35 years) was used as the forecasting or test period. In this work, 840 rules were created.

The training period comprises five years and provides sets with the input variables (d_1, d_2, and d_3) and the variation d. To create the rules, we identified the sets where each input variable (d_1, d_2, and d_3) is 100\% down or $100 \%$ up. These sets were called characteristics sets.

In characteristics sets, each input variable can be down or up. So, corresponding to the sequence $d \_1, d \_2$, and $d \_3$, one can find eight different types of characteristics sets: (down, down, down), (down, down, up), (down, up, 
down), (down, up, up), (up, down, down), (up, down, up), (up, up, down), and (up, up, up).

The variation $d$ was analyzed for each type of sequence to find out patterns of behaviors and create the rules. For example, analyzing the sequence (up, up, up) and the corresponding variation $d$ in the period from 1995 to 1999 , there are 53\% chances of down, $11 \%$ chances of flat, and $36 \%$ chances of up behaviors. With this information, inference rules were created to use in the year 2000.

The inference rules can reflect the behavior of traders in a specific market. If correct, a strategy based on these rules could help investors forecast the direction sign of the change.

\subsubsection{Output Variables}

The output of the model is denominated $\mathrm{d}$, which represents the variation of the index on the day of the forecast. The outputs of the linguistic values adopted were down, flat, and up. In this work, defuzzification was not necessary. The linguistic values were used as output variables, corresponding to the probability of the index showing a down, flat, or up behavior.

The output variable $\mathrm{d}$ can be represented as a vector of dimension $3 \times 1$, as shown next:

$$
d=\left[\begin{array}{l}
d 1 \\
d 2 \\
d 3
\end{array}\right],
$$

where $d 1$ is the linguistic component "down" of output $\mathrm{d}, d 2$ is the linguistic component "flat" of output $\mathrm{d}$, and $d 3$ is the linguistic component "up" of output d.

\subsection{Metrics}

In order to evaluate the results obtained from the proposed model, two different metrics were used: (1) the comparison of an investment strategy based on the fuzzy model with a passive strategy, and (2) a success ratio. These metrics are described next.

\subsubsection{Investment Strategy}


In general, it is a standard practice to test the created model through a real application via an investment strategy (e.g., see Brooks, Rew \& Ritson, 2001; Kuo, Chen \& Hwang, 2001; Haefke \& Helmestein, 2002; Kim \& Han, 2001; Leung, Daouk \& Chen, 2000; Chen, Leung \& Daouk, 2003; Leigh, Purvis \& Ragusa, 2002; Leigh, Modani \& Hightower, 2004; Leigh, Hightower \& Mondani, 2005; Armano, Marchesi \& Murru; 2005).

In this study, after the model estimation had been completed, a buying-andselling strategy was applied to the S\&P 500 index. This strategy can be viewed as a market timing strategy where one can switch between asset classes (from stock market index to risk-free cash and vice versa) in anticipation of the turning points in the market.

The two indices served as surrogates for an investment fund in risky assets. On the days on which the linguistic component "down" is greater than a variable called $\varepsilon$, the money is withdrawn from the fund, and applied again the next day. For example, if $\varepsilon=.5$, it means that the money will be withdrawn from the fund when the "down" possibility, indicated by the fuzzy model, is greater than $50 \%$. Implicit in this strategy is the supposition that the fund is able to buy and sell stocks in the same proportion as the stocks in the market index.

Concisely, the algorithm used was

If $\left(d 1_{i}>\varepsilon\right)$,

Then $\alpha_{i}=0$.

Else $\alpha_{i}=1$,

where $d 1_{i}$ is the linguistic component "down" for day i, $\alpha_{i}=1$ means that the money should be applied in the fund on day $\mathrm{i}$, and $\alpha_{i}=0$ means that the money should be withdrawn from the fund on day $i$.

The value of variable $\varepsilon$ is important. For one year, $\varepsilon=.5$ could be the value of $\varepsilon$ that maximizes the return. However, that value of $\varepsilon$ could not be the most profitable to other years. The investor wants to know what value of $\varepsilon$ will be adopted before trading. In other words, the $\varepsilon$ should be defined ex-ante. In this study, the value of $\varepsilon$ that maximizes the return in a year should be used the next year. For example, the value $\varepsilon=.52$ maximizes the return in the year 1975, so this value of $\varepsilon$ should be used in the year 1976. The year 1975 was the first year with inference rules (estimated from the 1970-1974 period) and has no value of $\varepsilon$ to be 
adopted. So, this year is not used to test the investment strategy. The value of $\varepsilon$ that maximizes the return in the year 1975 will be used in the strategy by the year 1976 and so on.

The fuzzy strategy should be compared with a passive one in order to check its usefulness. The following formula was used to calculate the buy-and-hold (passive) strategy returns:

$$
\prod_{i=1}^{n}\left(1+V a r_{d i} / 100\right)
$$

where $\operatorname{Var}_{d}$ is the percentage variation (in numeric value) of the daily variation or return of the index in day di. Actually, the value depicted in the equation just cited is the cumulative return from the index during the test period (with $\mathrm{n}$ trading days).

The return with the fuzzy-based strategy was calculated by the following formula:

$$
\prod_{i=1}^{n}\left[\alpha_{i} \times\left(1+\operatorname{Var}_{d i} / 100\right)+\left(1-\alpha_{i}\right)\right]
$$

For the simulation, the premise of a "frictionless market" was adopted. In other words, all transaction costs were considered nonexistent. This is not a problem, because when our investment strategy is compared with the returns of the stock market index, the costs related to the quarterly rebalancing of these indices were not take into account. In addition, the return that could be achieved by investing in the open market on days when the money is withdrawn from the fund was not taken into account.

\subsubsection{Success Ratio and Chi-Square test}

Besides testing a forecasting model through an investment strategy, it is also possible to test the "success ratio" of the model. Several authors used this approach (e.g., see Brooks, Rew \& Ritson, 2001; Kuo, Chen \& Hwang, 2001; Pérez-Rodrigues, Torra \& Andrada-Félix, 2005; Chun \& Park, 2004; Leung, Daouk \& Chen, 2000; Chen, Leung \& Daouk, 2003; Kim, 2004; Kim, Min \& Han, 2006; Armano, Marchesi \& Murru; 2005; Panda \& Narasimhan, 2006).

The success ratio was used to analyze the model's efficiency. This ratio compares the number of correct predictions with the total predictions. The statistical test used to check this efficiency was the chi-square test. It verified 
whether the set of days with "down" predictions presented a distribution of "down" and "up" outputs and was statistically different from the set of days with no "down" predictions.

\subsection{Choice of D}

At first, the strategy was developed with $\mathrm{D}=0.2 \%$. New rules were generated for a series of values of D $(0.0 \% ; 0.1 \% ; 0.3 \% ; 0.4 \%)$. Based on these rules, we can calculate the cumulative returns associated with each $\mathrm{D}$ value and verify whether $0.2 \%$ is a good choice.

In addition, we can verify whether fuzzy logic use brings better results compared with classical logic. The performance could have originated from rules and not by fuzzy logic use. When $\mathrm{D}=0 \%$, we are using classical logic. The fuzzy logic strategy (with $\mathrm{D}=0.2 \%$ ) should be compared with a classical logic strategy $(\mathrm{D}=0 \%)$ in order to check its usefulness.

\section{RESULTS}

The strategy was simulated in the period from 1976 to 2010. Table 2 presents these results using formulas from section 3.2.1.

The buy-and-hold strategy shows an average annual return of $7.82 \%$ for the test period. Table 2 shows that the fuzzy-based strategy presents an average annual return of 13.04 in the same period. In the case of absolute values, the fuzzy model outperforms the passive strategy by $5.22 \%$ a year, with a one-tailed $t$ statistics of 2.23, significant at the $5 \%$ level.

During the test period, the fuzzy-based strategy outperforms the passive strategy in 19 years, underperforms in 7 years, and has the same return in 9 years. The strategy is particularly profitable in the years of crises, when S\&P 500 exhibits a negative return.

Figure 4 shows the difference between passive and fuzzy-based strategy returns during the period from 1976 and 2010. 


\begin{tabular}{|c|c|c|c|}
\hline Year & (a) Fuzzy & (b) S\&P 500 & Differential return (a-b) \\
\hline 1976 & $22.31 \%$ & $19.15 \%$ & $3.16 \%$ \\
\hline 1977 & $0.82 \%$ & $-11.50 \%$ & $12.32 \%$ \\
\hline 1978 & $10.34 \%$ & $1.06 \%$ & $9.28 \%$ \\
\hline 1979 & $18.30 \%$ & $12.31 \%$ & $5.99 \%$ \\
\hline 1980 & $18.08 \%$ & $25.77 \%$ & $-7.70 \%$ \\
\hline 1981 & $-9.73 \%$ & $-9.73 \%$ & $0.00 \%$ \\
\hline 1982 & $28.85 \%$ & $14.76 \%$ & $14.09 \%$ \\
\hline 1983 & $11.97 \%$ & $17.27 \%$ & $-5.31 \%$ \\
\hline 1984 & $1.41 \%$ & $1.40 \%$ & $0.01 \%$ \\
\hline 1985 & $8.94 \%$ & $26.33 \%$ & $-17.40 \%$ \\
\hline 1986 & $14.62 \%$ & $14.62 \%$ & $0.00 \%$ \\
\hline 1987 & $5.86 \%$ & $2.03 \%$ & $3.83 \%$ \\
\hline 1988 & $12.40 \%$ & $12.40 \%$ & $0.00 \%$ \\
\hline 1989 & $27.25 \%$ & $27.25 \%$ & $0.00 \%$ \\
\hline 1990 & $-6.56 \%$ & $-6.56 \%$ & $0.00 \%$ \\
\hline 1991 & $13.49 \%$ & $26.31 \%$ & $-12.81 \%$ \\
\hline 1992 & $5.12 \%$ & $4.46 \%$ & $0.66 \%$ \\
\hline 1993 & $6.01 \%$ & $7.06 \%$ & $-1.05 \%$ \\
\hline 1994 & $4.19 \%$ & $-1.54 \%$ & $5.72 \%$ \\
\hline 1995 & $24.08 \%$ & $34.11 \%$ & $-10.03 \%$ \\
\hline 1996 & $20.26 \%$ & $20.26 \%$ & $0.00 \%$ \\
\hline 1997 & $31.01 \%$ & $31.01 \%$ & $0.00 \%$ \\
\hline 1998 & $27.59 \%$ & $26.67 \%$ & $0.92 \%$ \\
\hline 1999 & $33.54 \%$ & $19.53 \%$ & $14.02 \%$ \\
\hline 2000 & $2.14 \%$ & $-10.14 \%$ & $12.28 \%$ \\
\hline 2001 & $5.93 \%$ & $-13.04 \%$ & $18.98 \%$ \\
\hline 2002 & $15.63 \%$ & $-23.37 \%$ & $38.99 \%$ \\
\hline 2003 & $3.58 \%$ & $26.38 \%$ & $-22.80 \%$ \\
\hline 2004 & $12.52 \%$ & $8.99 \%$ & $3.53 \%$ \\
\hline 2005 & $8.72 \%$ & $3.00 \%$ & $5.72 \%$ \\
\hline 2006 & $19.09 \%$ & $13.62 \%$ & $5.47 \%$ \\
\hline 2007 & $3.53 \%$ & $3.53 \%$ & $0.00 \%$ \\
\hline 2008 & $26.70 \%$ & $-38.49 \%$ & $65.18 \%$ \\
\hline 2009 & $34.05 \%$ & $23.45 \%$ & $10.59 \%$ \\
\hline 2010 & $12.78 \%$ & $12.78 \%$ & $0.00 \%$ \\
\hline Mean & $13.04 \%$ & $7.82 \%$ & $5.22 \%(*)$ \\
\hline
\end{tabular}

Notes:

(*) means statistically significant at $5 \%$, one-tailed t-test;

$\mathrm{S} \& \mathrm{P} 500$ is the proxy for the buy-and-hold (passive) strategy.

Table 2. Returns for the fuzzy and passive strategies, from 1976 to 2010. 


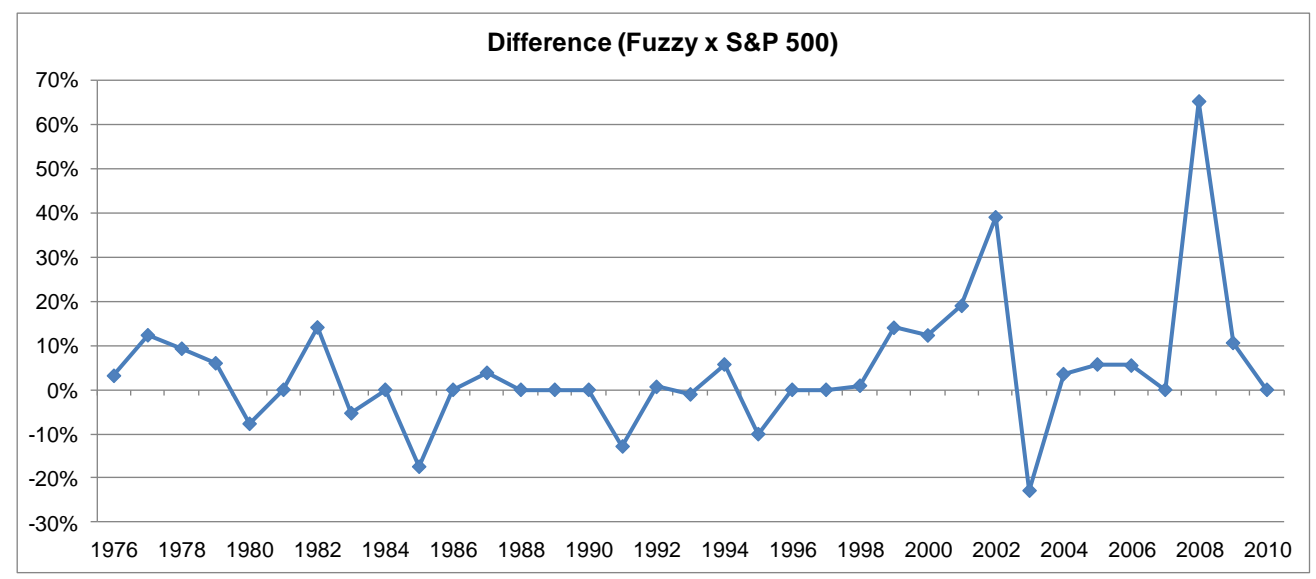

Notes:

Horizontal axis represents the years of the test period;

Vertical axis represents the difference between fuzzy strategy and S\&P 500 in each year.

Figure 4. Difference between passive and fuzzy-based strategy from 1976 and 2010.

Figure 5 shows the passive (S\&P 500) and fuzzy strategy returns of one monetary unit invested at the beginning of the test period (January 1, 1976).

At the end of the test period (December 31, 2010), the passive S\&P 500 would return 13.94 monetary units, and the fuzzy-based strategy would return 72.87 monetary units.

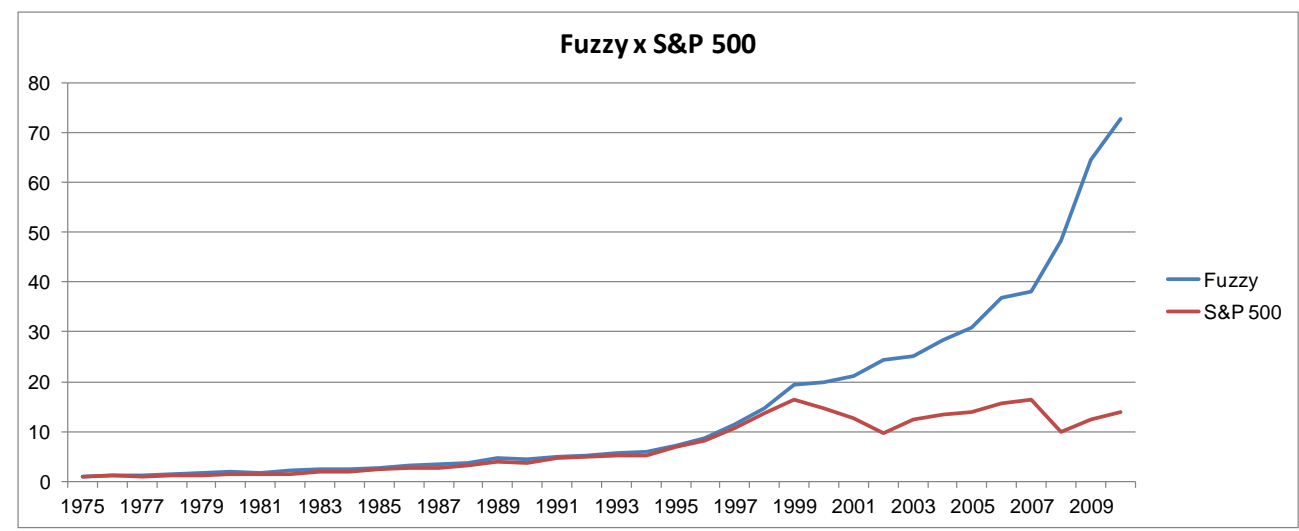

Notes:

Horizontal axis represents the years of the test period;

Vertical axis represents the value of one monetary unit invested at the beginning of the test period.

Figure 5. Cumulative returns of the passive (S\&P 500) and fuzzy-based strategy. 
In addition, the success rate on the days of money withdrawal was calculated. A success ratio of $50.81 \%$ was achieved. The money would be withdrawn in 2647 days, and the index would fall on 1345 of these days. The chi-square $\left(\chi^{2}=20.12\right)$ was statistically significant at the $1 \%$ level.

\subsection{Strategy after Leman Brothers Failure}

Figure 6 presents a graphic depiction with the cumulative returns of one monetary unit invested using a fuzzy and passive strategy on August 28, 2008, a few days before the Leman Brothers collapse. At the end of the test period (December 31,2010 ), the passive S\&P 500 would return 0.98 monetary units, and the fuzzy-based strategy would return 1.69 monetary units.

The fuzzy strategy outperforms the passive one, with a one-tailed t statistics of 1.77 , significant at the $5 \%$ level.

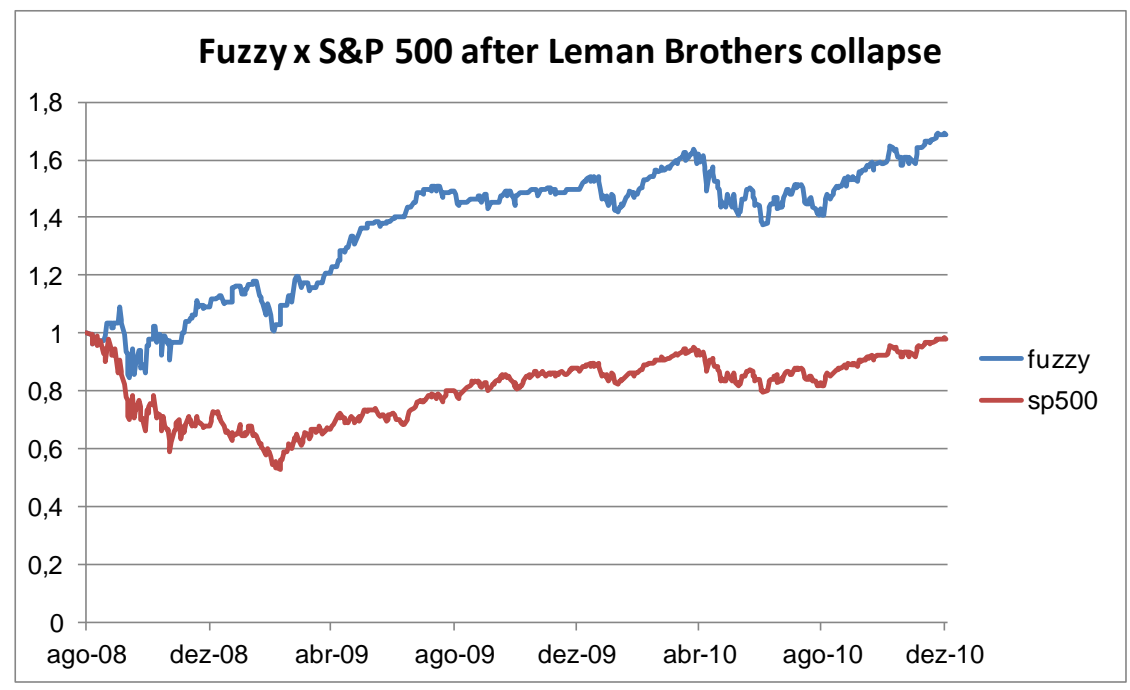

Notes:

Horizontal axis represents the days of the test period;

Vertical axis represents the value of one monetary unit invested at the beginning of the test period.

Figure 6. Cumulative returns of the fuzzy-based strategy and S\&P 500 after Leman Brothers collapse 


\subsection{Choice of $D$}

At first, the strategy was developed with $\mathrm{D}=0.2 \%$. New rules were generated for a series of values of $\mathrm{D}(0.0 \% ; 0.1 \% ; 0.3 \% ; 0.4 \%)$.

Figure 7 presents a graphic depiction with the cumulative returns (of one monetary unit invested at the beginning of the test period) for each $\mathrm{D}$ value.

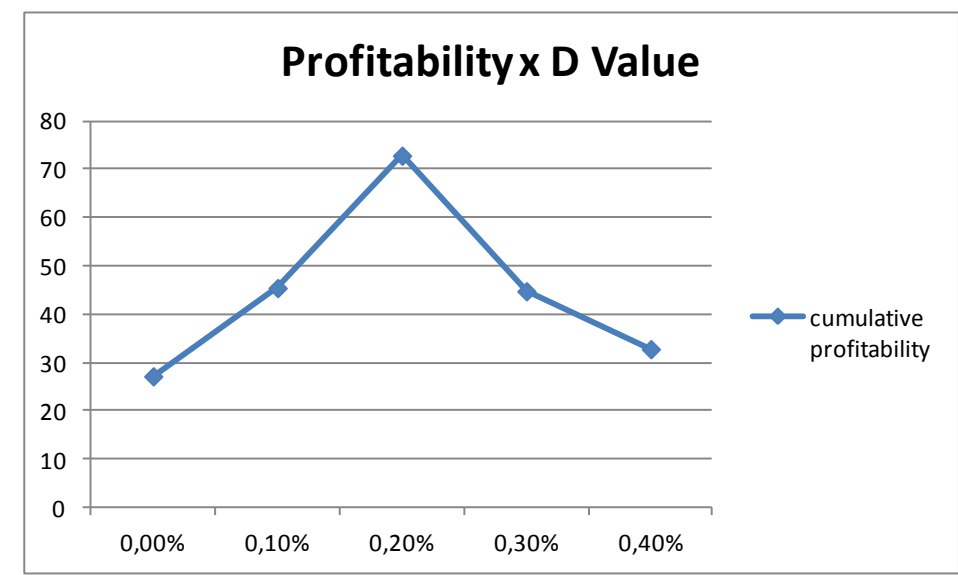

Notes:

Horizontal axis represents the D values;

Vertical axis represents the final value of one monetary unit invested at the Beginning of the test period.

Figure 7. Fuzzy strategy cumulative returns for each D value.

As observed in Figure 7, if the D value is too small, then the profitability of the strategy is similar to that obtained with classical logic. On the other hand, if the D value are too large, then the profitability falls.

The profitability of fuzzy logic (using $\mathrm{D}=0.2 \%$ ) is superior to classical logic $(\mathrm{D}=$ $0 \%$ ), with a one-tailed $t$ statistics of 1.88 , significant at the $5 \%$ level.

\section{CONCLUSION}

This article presents a new approach, based on fuzzy logic, for forecasting the direction of movements of the S\&P 500 index. The period from 1970 to 2009 was used to establish the rules of the model, and the period from 1976 to 2010 was used to test the model.

The proposed model returned a non-exact answer, with a probabilistic output. Despite this imprecision, it was possible to estimate a statistically significant (5\%) 
buying-and-selling strategy that outperformed a buy-and-hold (passive) one for the test period. The fuzzy-based strategy outperformed the passive strategy. Further, the success rate calculated was statistically significant (1\%).

Why does the fuzzy strategy outperform the passive one? The strategy seeks to avoid financial loss on days where the probability of the stock index fall is high. Therefore, the strategy is particularly profitable in the years of crises, when the S\&P 500 exhibits a negative return. For example, after the Leman Brothers collapse.

However, the fuzzy logic model outperforms the application of a similar classical logic model. Fuzzy logic outperformed classical logic at the 5\% significance level.

The proposed model, with its probabilistic output, can be used as a support to investment decisions, as investors could have other information, secrets, or otherwise or even intuitions about political influences or economic tendencies. For example, if the "down" possibility (indicated by the fuzzy model) is greater than $\varepsilon$ the money should be withdrawn from the fund, however the investor can use complementary information and decides do not withdrawn. In other words, the linguistic output does not force the investor follow blindly the strategy.

There are many new research possibilities that could be derived from this work. One of them is the choice of new input variables and linguistic terms. For example, the procedure could be applied to weekly and monthly forecasts that could bring good results and reduce transaction costs. Another possibility would be the inclusion in the model of some well-known stock market anomalies (e.g. day-of-the-week or month-of-the-year effects), as well as rules from technical analysis. In addition, other artificial intelligence techniques, such as ANN, could be associated with the models based on fuzzy logic.

\section{REFERENCES}

AGGARWAL, R.; DEMASKEY, A. (1997): "Using derivatives in major currencies for cross-hedging currency risks in Asian emerging markets", Journal of Futures Markets, vol. 17: 781-796. http://dx.doi.org/10.1002/(SICI)10969934(199710)17:7<781::AID-FUT3>3.0.CO;2-J

ARMANO, G.; MARCHESI, M.; MURRU, A. (2005): "A hybrid genetic-neural architecture for stock indexes forecasting”, Information Sciences, vol. 170: 3-33. http://dx.doi.org/10.1016/j.ins.2003.03.023 
ATSALAKIS, G. S.; VALAVANIS, K. P. (2009): "Forecasting stock market short-term trends using a neuro-fuzzy based methodology", Expert Systems with Applications, vol. 36: 10696-10707. http://dx.doi.org/10.1016/j.eswa.2009.02.043

BEYNON, M.J.; PEEL, M.J.; TANG, Y. (2004): “The application of fuzzy decision tree analysis in an exposition of the antecedents of audit fees", The International Journal of Management Science, vol. 32: 231-244. http://dx.doi.org/ $\underline{10.1016 / \text { j.omega.2003.11.003 }}$

BOJADZIEV, G.; BOJADZIEV, M. (1997): Fuzzy logic for business, finance and management. Singapore: World Scientific.

BOYACIOGLU, M. A.; AVCI, D. (2010): “An adaptaptative network-based fuzzy inference system (ANFIS) for the prediction of stock market return: the case of the Istanbul Stock Exchange", Expert Systems with Applications, vol. 37: 79087912. http://dx.doi.org/10.1016/j.eswa.2010.04.045

BROOKS, C.; REW, A. G.; RITSON, S. (2001): "A trading strategy based on the lead-lag relationship between the spot index and futures contract for the FTSE 100", International Journal of Forecasting, vol. 17: 31-44. http://dx.doi.org/10.10 16/S0169-2070(00)00062-5

CHAKRABORTY, M. (2006): "Market efficiency for the Pakistan stock market: evidence from the Karachi stock exchange", South Asia Economic Journal, vol. 7, n. 1: 67-81. http://dx.doi.org/10.1177/139156140500700104

CHEN, T.; CHENG, C.; TEOH, H. (2007): "Fuzzy time-series based on fibonacci sequence for stock price forecasting", Physica A, 380: 377-390. http://dx.doi.org/10.1016/j.physa.2007.02.084

CHEN, T.; CHENG, C.; TEOH, H. (2008): "High-order fuzzy time-series based on multi-period adptation model for forecasting stock markets", Physica A, 387: 876-888. http://dx.doi.org/10.1016/j.physa.2007.10.004

CHEN, C.; HSIN, P.; WU, C. (2010): "Forecasting Taiwan's major indices by the Nash nonlinear grey Bernoulli model”, Expert Systems with Applications, vol. 37: 7557-7562. http://dx.doi.org/10.1016/j.eswa.2010.04.088

CHEN, H.; HUANG, S.Y.; LIN, C. (2009): "Alternative diagnosis of coporate bankruptcy: a neuro fuzzy approach", Expert Systems with Applications, v. 36: 7710-7720. http://dx.doi.org/10.1016/j.eswa.2008.09.023

CHEN, A.; LEUNG, M.T.; DAOUK, H. (2003): "Application of neural networks to an emerging financial market: forecasting and trading the Taiwan stock index", Computers \& Operational Research, vol. 30: 901-923. http://dx.doi.org/10.1016/S 0305-0548(02)00037-0

CHENG, C.; WEI, L.; CHEN, Y. (2009): "Fusion ANFIS models based on multi- 
stock volatility causality for TAEIX forecasting”, Neurocomputing, vol. 72: 34623468. http://dx.doi.org/10.1016/j.neucom.2008.09.027

CHENG, M.; TSAI, H.; SUDJONO, E. (2010): "Evolutionary fuzzy hybrid neural network for project cash flow control", Engineering Applications of Artificial Intelligence, vol. 23: 604-613. http://dx.doi.org/10.1016/j.engappai.2009.10.003

CHU, H.; CHEN, T.; CHENG, C.; HUANG, C. (2009): "Fuzzy dual-factor timeseries for stock index forecasting", Expert Systems with Applications, vol. 36: 165-171. http://dx.doi.org/10.1016/j.eswa.2007.09.037

CHUN, S.; KIM, K.; KIM, S.H. (2002): "Chaotic analysis of predictability versus knowledge discovery techniques: case study of the Polish stock market", Expert Systems, vol. 19, n. 5: 264-272.

CHUN, S.; PARK, Y. (2006): "A new hybrid data mining technique using a regression case based reasoning: application to financial forecasting", Expert Systems with Applications, vol. 31: 329-336. http://dx.doi.org/10.1016/j.eswa.200 $\underline{5.09 .053}$

DOURRA, H.; SIV, P. (2002): "Investment using technical analysis and fuzzy logic", Fuzzy Sets and Systems, 127, 221-240. http://dx.doi.org/10.1016/S0165$\underline{0114(01) 00169-5}$

DUTTA, G.; JHA, P.; LAHA, A.K.; MOHAN, N. (2006): "Artificial neural network models for forecasting stock price index in Bombay stock exchange", Journal of Emerging Market Finance, vol. 5, n. 3: 283-295. http://dx.doi.org/10.1177/097265270600500305

FAMA, E.F.; FRENCH, K.R. (1988): "Permanent and temporary components of stock prices", Journal of Political Economics, vol. 96, n.2: 246-273.

FARIA, E.L.; ALBUQUERQUE, M.P.; GONZALES, J.L.; CAVALCANTE, J.T.P.; ALBUQUERQUE, M.P. (2009): "Predicting the Brazilian stock market through neural networks and adaptive exponential smoothing methods", Expert Systems with Applications, vol. 36: 12506-12509. http://dx.doi.org/10.1016/j.eswa .2009 .04 .032

HADAVANDI, E.; SHAVANDI, H.; GHANBARI, A. (2010): "Integration of genetic fuzzy systems and artificial neural networks for stock price forecasting", Expert Systems with Applications, vol. 23: 800-808. http://dx.doi.org/10.1016/j.kn osys.2010.05.004

HAEFKE, C.; HELMENSTEIN. C. (2002): "Index forecasting and model selection", Intelligent Systems in Accounting, Finance and Management, v. 11, n. 2, p. 119-135. http://dx.doi.org/10.1002/isaf.214

HUARNG, K. (2001a): "Heuristic models of fuzzy time series for forecasting", 
Fuzzy Sets and Systems, vol. 123, n. 3: 369-386. http://dx.doi.org/10.1016/S01650114(00)00093-2

HUARNG, K. (2001b): "Effective lengths of intervals to improve forecasting in fuzzy time series", Fuzzy Sets and Systems, vol. 123, n. 3: 387-394. http://dx.doi.org/10.1016/S0165-0114(00)00057-9

HUARNG, K.; YU, H. (2005): “A type 2 fuzzy time series model for stock index forecasting", Physica A, 353: 445-462. http://dx.doi.org/10.1016/j.physa.2004.11. $\underline{070}$

HUARNG, K.; YU, H. (2006): "The application of neural networks to forecasting fuzzy time series", Physica A, 363: 481-491. http://dx.doi.org/10.1016/j.physa.200 $\underline{5.08 .014}$

INUIGUCHI, M.; TANINO, T. (2000): "Portfolio selection under independent possibilistic information", Fuzzy Sets and Systems, vol. 155: 83-92. http://dx.doi.org/10.1016/S0165-0114(99)00026-3

JIANG, B.: HSU, C. (2003): "Development of a fuzzy decision model for manufacturing", Journal of Intelligent Manufacturing, vol. 14: 169-181. http://dx.doi.org/10.1023/A:1022999313271

KAMITSUJI, S.; SHIBATA, R. (2003): "Effectiveness of stochastic neural network for prediction of fall or rise of TOPIX", Asia-Pacific Financial Markets, vol. 10: 187-204. http://dx.doi.org/10.1007/s10690-005-6010-4

KELES, A.; KOLCAK, M.; KELES, A. (2008): "the adaptative neuro-fuzzy model for forecasting the domestic debt", Knowledge-Based Systems, vol. 21: 951-957. http://dx.doi.org/10.1016/j.knosys.2008.04.007

KIM, K. (2004): "Artificial neural networks with feature transformation based on domain knowledge for the prediction of stock index futures", Intelligent Systems in Accounting, Finance and Management, vol. 12, n. 3: 167-176. http://dx.doi.org/10.1002/isaf.252

KIM, K.; HAN, I. (2001): "The extraction of trading rules from stock market data using rough sets”, Expert Systems, vol. 18, n. 4: 194-202.

KIM, M.; MIN, S.; HAN, I. (2006): "An evolutionary approach to the combination of multiple classifiers to predict a stock price index", Expert Systems with Applications, vol. 31:241-247. http://dx.doi.org/10.1016/j.eswa.2005.09.020

KUO, R. J.; CHEN, C. H.; HWANG, Y. C. (2001): “An intelligent stock trading decision support system through integration of genetic algorithm based fuzzy neural network and artificial neural network", Fuzzy Sets and Systems, vol.118: 21-45. http://dx.doi.org/10.1016/S0165-0114(98)00399-6

LEIGH, W.; HIGHTOWER, R.; MODANI, N. (2005): "Forecasting the New 
York stock exchange composite index with past price and interest rate on condition of volume spike", Expert Systems with Applications, vol. 28: 1-8. http://dx.doi.org/10.1016/j.eswa.2004.08.001

LEIGH, W.; MODANI, N.; HIGHTOWER, R. (2004): “A computational implementation of stock charting: abrupt volume increase as signal for movement in New York stock exchange composite index", Decision Support Systems, vol. 37: 515-530. http://dx.doi.org/10.1016/S0167-9236(03)00084-8

LEIGH, W.; PURVIS, R.; RAGUSA, J. M. (2002): "Forecasting the NYSE composite index with technical analysis, pattern regognizer, neural network, and genetic algorithm: a case study in romantic decision support", Decision Support Systems, vol. 32: 361-377. http://dx.doi.org/10.1016/S0167-9236(01)00121-X

LEÓN, T.; LIERN, V.; VERCHER, E. (2002): "Viability of infeasible portfolio selection problems: a fuzzy approach", European Journal of Operational Research, vol. 139: 178-189. http://dx.doi.org/10.1016/S0377-2217(01)00175-8

LEUNG, M.T.; DAOUK, H.; CHEN, A. (2000): "Forecasting stock indices: a comparison of classification and level estimation models. International", Journal of Forecasting, vol. 16: 173-190. http://dx.doi.org/10.1016/S0169-2070(99)00048-5

LIN, J.; HWANG, M.; BECKER, J. (2003): "A fuzzy neural network for accessing the risk of fraudulent financial reporting", Managerial Auditing Journal, vol. 18: 657-665. http://dx.doi.org/10.1108/02686900310495151

LO, A. W.; MACKINLAY, C. (1988): "Stock market prices do not follow random walks: evidence from a simples specification test", Review of Financial Studies, vol. 1, n.1: 41-66.

LU, C. (2010): "Integrating independent component analysis-based denoising scheme with neural network for stock price prediction", Expert Systems with Applications, vol. 37: 7056-7064. http://dx.doi.org/10.1016/j.eswa.2010.03.012

MAJHI, R.; PANDA, G.; MAJHI, B.; SAHOO, G. (2009): "Efficient prediction of stock market indices using adaptive bacterial foraging optimization (ABFO) and BFO based techniques", Expert Systems with Applications, vol. 36: 1009710104. http://dx.doi.org/10.1016/j.eswa.2009.01.012

MOSTAFA, M.M. (2010): "Forecasting stock exchange movements using neural networks: empirical evidence from Kuwait", Expert Systems with Applications, vol. 37: 6302-6309. http://dx.doi.org/10.1016/j.eswa.2010.02.091

MURCIA, F. D.; BORBA, J. A.; SOUTO-MAIOR, C. D. (2005): "Modeling the Subjectivity in the Target Costing Process: An Experimental Approach Based on the Fuzzy Logic Concepts", The International Journal of Digital Accounting Research, vol. 5, n. 10: 203-222. http://dx.doi.org/10.4192/1577-8517-v5 6 
NA, S.H.; SOHN, S.Y. (2011): "Forecasting changes in Korea Composite Stock Price Index (KOSPI)", Expert Systems with Applications, vol. 38:. 9046-9049. http://dx.doi.org/10.1016/j.eswa.2011.01.025

O'CONNOR, M.; REMUS, W.; GRIGGS, K. (1997): "Going up-going down: How good are people at forecasting trends and changes in trends?", Journal of Forecasting, vol. 16: 165-176. http://dx.doi.org/10.1002/(SICI)1099-131X(19970 5)16:3<165::AID-FOR653>3.0.CO;2-Y

PANDA, C.; NARASIMHAN, V. (2006): "Predicting stock returns: an experiment of the artificial neural network in Indian stock market", South Asia Economic Journal, vol. 7, n. 2: 205-218. http://dx.doi.org/10.1177/139156140600 $\underline{700203}$

PÉREZ-RODRÍGUES, J, v. P.; TORRA, S.; ANDRADA-FÉLIX, J. A. (2005): "STAR ANN models: forecasting performance on the Spanish "IBEX-35" stock index", Journal of Empirical Finance, vol. 12: 490-509. http://dx.doi.org/10.1016 /j.jempfin.2004.03.001

POTERBA, J.; SUMMERS, L. (1988): "Mean reversion in stock prices: evidence and implications", Journal of Financial Economics, vol. 22, n. 1: 27-59. http://dx.doi.org/10.1016/0304-405X(88)90021-9

SAHIN, U.; DOGAN, I. (2003): "Supplier selection using activity based costing and fuzzy present-worth techniques", Logistics Information Management, vol. 16: 420-426. http://dx.doi.org/10.1108/09576050310503394

SERGUIEVA, A.; HUNTER, J. (2004): "Fuzzy interval methods in investment risk appraisal", Fuzzy Sets and Systems, vol. 142: 443-466. http://dx.doi.org/10.1 016/S0165-0114(03)00166-0

SHEHAB, E.; ABDALLA, H. (2002): "Intelligent knowledge based system for product cost modeling", Advanced Manufacturing Technology, vol. 19: 49-65.

SHEN, W.; GUO, X.; WU, C.; WU, D. (2011): "Forecasting stock indices using radial basis function neural networks optimized by artificial fish swarm algorithm", Knowledge-Based Systems, vol. 24: 378-385. http://dx.doi.org/10.101 6/j.knosys.2010.11.001

SIMUTIS, R. (2000): "Fuzzy logic based stock rading system", Proc. IEEE/IAFE Conf. On Computational Intelligent of Financial Engineering, New York.

SOHN, S.Y.; LIM, M. (2007): "Hierarchical forecasting based on AR-GARCH model in a coherent structure", European Journal of Operational Research, vol. 176: 1033-1040. http://dx.doi.org/10.1016/j.ejor.2005.08.019

SOUTO-MAIOR, C. D. (2007): Forecast of the movement direction of stock market indices applying a fuzzy system. MBA Dissertation, Federal University of 
Santa Catarina.

TANAKA, H.; GUO, P. (1999): "Portfolio selection based on upper and lower exponential possibility distributions", European Journal of Operational Research, vol. 114: 115-126. http://dx.doi.org/10.1016/S0377-2217(98)00033-2

TEIXEIRA, J. C.; RODRIGUES, A. J. (1997): “An applied study on recursive estimation methods, neural networks and forecasting", European Journal of Operational Research, vol. 101: 406-417. http://dx.doi.org/10.1016/S03772217(96)00406-7

TEOH, H. J; CHEN, T.; CHENG, C.; CHU, H. (2009): “A hybrid multi-order fuzzy time series for forecasting stock markets", Expert Systems with Applications, vol. 36: 7888-7897. http://dx.doi.org/10.1016/j.eswa.2008.11.009

TEOH, H. J; CHENG, C.; CHU, H.; CHEN, J. (2008): "Fuzzy time series model based on probabilistic approach and rough set rule induction for empirical research in stock markets", Data and Knowledge Engineering, vol. 67: 103-117. http://dx.doi.org/10.1016/j.datak.2008.06.002

THAVANESWARAN, A.; APPADOO, S. S.; PASEKA, A. (2009): "Weighted possibilistic moments of fuzzy numbers with applications to GARCH modeling and option pricing", Mathematical and Computer Modelling, vol. 49: 352-368. http://dx.doi.org/10.1016/j.mcm.2008.07.035

TIRYAKI, F.; AHLATCIOGLU, B. (2009): "Fuzzy portfolio selection using fuzzy analytic hierarch process", Information Sciences, vol. 179: 53-69. http://dx.doi.org/10.1016/j.ins.2008.07.023

TSAIH, R.; HSU, Y.; LAI, C.C. (1998): "Forecasting S\&P 500 stock index futures with a hybrid AI system", Decision Support Systems, vol. 23: 161-174. http://dx.doi.org/10.1016/S0167-9236(98)00028-1

TSENG, F.M.; LIN, L. (2005): “A quadratic interval logit model for forecasting bankruptcy", Omega, vol. 33: 85-91. http://dx.doi.org/ 10.1016/j.omega.2004.04.002

VIGIER, H. P.; TERCEÑO, A. (2008): "A model for the prediction of "diseases" of firms by means of fuzzy relations", Fuzzy Sets and Systems, vol. 159: 22992316. http://dx.doi.org/10.1016/j.fss.2008.01.015

VON ALTROCK, C. (1997): Fuzzy logic and neurofuzzy applications in business and finance. Upper Saddle River: Prentice Hall.

WANG, F.; CHANG, K.; TZENG, C. (2011): "Using adaptative network-based fuzzy inference system to forecast automobile sales", Expert Systems with Applications, vol. 38: 10587-10593. http://dx.doi.org/10.1016/j.eswa.2011.02.100

WANG, Y.; CHENG, S.; HSU, M. (2010): "Incorporating the Markov chain concept into fuzzy stochastic prediction of stock indexes", Applied Soft 
Computing, vol. 10: 613-617. http://dx.doi.org/10.1016/j.asoc.2009.08.028

WANG, C.; HSU, L. (2008): "Constructing and applying an improved fuzzy time series model: taking the tourism industry for example", Expert Systems with Applications, vol. 34: 2732-2738. http://dx.doi.org/10.1016/j.eswa.2007.05.042

WANG, S.; ZHU, S. (2002): “On fuzzy portfolio selection problems”, Fuzzy Optimization and Decision Making, vol. 1, n. 4: 361-377. http://dx.doi.org/10.102 3/A:1020907229361

WU, Q. (2010): "Regression application based on fuzzy v-suport vector machine in symmetric triangular fuzzy space", Expert Systems with Applications, vol. 37: 2808-2814. http://dx.doi.org/10.1016/j.eswa.2009.09.010

WU, Q. (2011): "Fuzzy robut v-suport vector machine with penalizing hybrid noises on symmetric triangular fuzzy number space", Expert Systems with Applications, vol. 38: 39-46. http://dx.doi.org/10.1016/j.eswa.2010.06.003

WU, Y.; ZHANG, H. (1997): "Forward premiums as unbiased predictors of future currency depreciation: a non-parametric analysis", Journal of International Money and Finance, vol. 16, n. 4: 609-623. http://dx.doi.org/10.1016/S02615606(97)00022-3

YEH, C.; HUANG, C.; Lee, S. (2011): "A multiple-kernel support vector regression approach for stock market price forecasting", Expert Systems with Applications, vol. 38: 2177-2186. http://dx.doi.org/10.1016/j.eswa.2010.08.004

YU, H. (2005a): "A refined fuzzy time-series for forecasting", Physica A, vol. 346: 657-681. http://dx.doi.org/10.1016/j.physa.2004.07.024

YU, H. (2005b): "Weighted fuzzy time series models for TAIEX forecasting", Physica A, vol. 349: 609-624. http://dx.doi.org/10.1016/j.physa.2004.11.006

YU, T. H.; HUARNG, H. (2008): “A bivariate fuzzy time series model to forecast the TAIEX", Expert Systems with Applications, vol. 34: 2945-2952. http://dx.doi.org/10.1016/j.eswa.2007.05.016

YU, T. H.; HUARNG, H. (2010): “A neural network-based time series model to improve forecasting", Expert Systems with Applications, vol. 37: 3366-3372. http://dx.doi.org/10.1016/j.eswa.2009.10.013

ZADEH, L. (1965): Fuzzy Sets, Information and Control, vol. 8: 338-353. http://dx.doi.org/10.1016/S0019-9958(65)90241-X

ZEBDA, A. (1998): "The problem of ambiguity and the use of fuzzy set theory in accounting: a perspective and opportunities for research". In SIEGEL, H.P.OMER, K.; de KORVIN, A.; EPSTEIN, M. (Eds.) Applications of fuzzy sets and the theory of evidence to accounting, (pp. 20-33). London: Jai Press. 